\title{
The Impact of Gain- and Loss-Framed Messages on Young Adults' Sexual Decision Making: An Experimental Study
}

\author{
Kathryn Macapagal ${ }^{1,2}$ (1) $\cdot$ Erick Janssen $^{2,3} \cdot$ Margaret Matson $^{4} \cdot$ Peter R. Finn $^{5} \cdot$ \\ Julia R. Heiman ${ }^{2,5}$
}

Received: 9 March 2015 / Revised: 20 November 2015 / Accepted: 7 December 2015

(C) Springer Science+Business Media New York 2015

\begin{abstract}
Messages that frame a target behavior in terms of its benefits (gain frame) or costs (loss frame) have been widely and successfully used for health promotion and risk reduction. However, the impact of framed messages on decisions to have sex and sexual risk, as well as moderators of these effects, has remained largely unexplored. We used a computerized laboratory task to test the effects of framed messages about condom use on young adults' sexual decision making. Participants $(N=127)$ listened to both gain- and loss-framed messages and rated their intentions to have sex with partners who posed a high and low risk for sexually transmitted infections (STIs). The effects of message frame, partner risk, participant gender, ability to adopt the messages, and message presentation order on intentions to have sex were examined. Intentions to have sex with high-risk partners significantly decreased after the loss-framed message, but not after the gainframed message, and intentions to have sex increased for partic-
\end{abstract}

Kathryn Macapagal

kathryn.macapagal@northwestern.edu

1 Department of Medical Social Sciences, Northwestern University Feinberg School of Medicine, 625 North Michigan Avenue, Suite 2700, Chicago, IL 60611, USA

2 The Kinsey Institute for Research in Sex, Gender, and Reproduction, Indiana University, Bloomington, IN, USA

3 Institute for Family and Sexuality Studies, Department of Neurosciences, University of Leuven, Leuven, Belgium

4 Richard M. Fairbanks School of Public Health, Indiana University-Purdue University Indianapolis, Indianapolis, IN, USA

5 Department of Psychological and Brain Sciences, Indiana University, Bloomington, IN, USA ipants who received the gain-framed message first. Yet, participants found it easier to adopt the gain-framed message. Results suggest that loss-framed messages may be particularly effective in reducing intentions to have sex with partners who might pose a higher risk for STIs, and that message presentation order may alter the relative effectiveness of gain- and loss-framed messages on sexual decision making. Future studies should examine the precise conditions under which gain- and loss-framed messages can promote healthy sexual behaviors and reduce sexual risk behaviors.

Keywords Message framing · Sexual risk taking · Sexual decision making $\cdot$ Young adults

\section{Introduction}

Sexually transmitted infections (STIs) continue to be a significant public health concern in the United States. Adolescents and emerging adults aged 15-24 are disproportionately affected by STIs, accounting for half of the nearly 20 million new infections annually (Centers for Disease Control and Prevention [CDC], 2014). Given that STIs can have substantial negative effects on young adults' health, relationships, and well-being (United States Department of Health and Human Services, Healthy People 2020, 2013), there remains a need for research on health communications targeted at improving sexual health behaviors and reducing STI risk behaviors in this population. One strategy that has received increased attention in the sexual health literature is message framing, which describes health behaviors in terms of the benefits (i.e., gain-framed) or the costs of not adopting the behavior (i.e., lossframed) (Rothman \& Salovey, 1997; Tversky \& Kahneman, 1981). Framing has been shown to impact attitudes toward and intentions to engage in sexual health behaviors, including STI or HIV testing (e.g., Apanovitch, McCarthy, \& Salovey, 2003; Garcia-Retamero 
\& Cokely, 2011; Hull, 2012), human papillomavirus (HPV) vaccinations (e.g., Gerend \& Shepherd, 2007), and condom use (e.g., Garcia-Retamero \& Cokely, 2011; Richardson et al., 2004). However, how framed messages may alter individuals' decisions to have sex altogether, and the conditions under which different frames are effective for sexual risk reduction, remain understudied. The present study examined the impact of gain- and loss-framed messages on young adults' decisions to have sex with potential partners who pose a high and low risk for STIs, as well as potential moderators of the framing effects.

\section{Message Framing in Sexual Health Research}

Message framing is based on prospect theory (Tversky \& Kahneman, 1981), a behavioral economic theory that posits that framing a behavior in terms of its prospective costs (loss-framed; for example, "If you don't use condoms, you would put yourself at risk for STIs") or benefits (gain-framed; for example, "If you do use condoms, you would protect yourself from STIs") can have significantly different effects on individuals' decision making. An extension of this theory to health behavior proposed that individuals' receptivity to different message frames would depend on the perceived risk or function of the behavior being advocated by the message (Rothman \& Salovey, 1997). Specifically, loss-framed messages were proposed to be more effective when advocating behaviors associated with greater risk or uncertainty (e.g., disease detection behaviors like STI testing, which involves some risk of detecting an undesired illness). In contrast, gain-framed messages were proposed to be more persuasive when advocating behaviors associated with relatively safe or certain outcomes (e.g., preventive behaviors like condom use, which are highly effective if used correctly).

While individual studies have shown support for this theory, a meta-analysis indicated that applications of message framing to sexual health behaviors like STI/HIV testing, HPV vaccinations, and condom use have yielded mixed results, with no clear advantage for either gain- or loss-framed messages (Gallagher \& Updegraff, 2012). In addition, while the outcomes studied in the sexual health framing literature to date fit neatly into "detection" or "prevention" behaviors, this dichotomy does not apply to the decision to have sex itself. To our knowledge, only one study has applied message framing to sexual decision making. Camenga et al. (2014) examined young adolescents' preferences for gain- and loss-framed health promotion materials aimed at delaying sexual initiation. While results suggested that a combination of both frames was preferred, this study did not examine how the frames affected actual decisions to have sex. As such, how message framing may influence sexual decisions (e.g., hooking up with a casual sex partner, having sex with a partner with a history of condom non-use) remains unclear.

\section{Factors Impacting Sexual Health Message Framing Effects}

\section{Individual Characteristics}

Inconsistent findings in past framing research are attributed to the fact that different message frames work differently for different people, target behaviors, and situations (Covey, 2014). A wellestablished moderator of message framing effects on sexual health behavior is the extent to which the individual receiving the message may be at risk for HIV or STIs. For example, among persons with a high-risk sexual history (e.g., multiple concurrent sex partners and history of infrequent condom use), loss-framed messages were more effective than gain-framed messages at reducing rates of condomless sex, whereas framing effects did not differ among participants with a lower risk sexual history (Richardson et al., 2004). Relatedly, one's perceived risk of contracting STIs or HIV can alter the effectiveness of each frame, with loss-framed messages more effective at increasing intentions to be tested for HIV among women with higher perceived risk of HIV, and gainframed messages more effective among women with lower perceived risk (Hull, 2012). Together, messages focused on the drawbacks of risky sexual behavior may be more effective among individuals who are, or perceive themselves to be, at high risk for unwanted sexual health outcomes.

Other individual factors have been less well studied in the sexual health framing literature. It has been hypothesized that gender may moderate message framing effects due to gender differences in risk perception (Toll et al., 2008). As young women are shown to perceive more benefits to safe sex and greater costs of unprotected sex than young men (e.g., Parsons, Halkitis, Bimbi, \& Borkowski, 2000), one may expect that the impact of messages advocating the benefits of safe sex versus messages highlighting the costs of unsafe sex may differ by gender. To date, the few studies that have investigated gender differences in sexual health message framing yield equivocal results, with some finding no significant differences (Block \& Keller, 1995; Kiene, Barta, Zelenski, \& Cothran, 2005), and others showing within-gender differences (O'Connor, Ferguson, \& O'Connor, 2005). In addition, an individual's ability to subjectively internalize, adopt, or "buy into" the content of sexual health messages may increase message persuasiveness or effectiveness. For example, greater message elaboration, or the ability to deeply consider and think about the content of messages, was associated with stronger effects of both gain- and loss-framed messages promoting HIV testing (Hull, 2012). In addition, women who rated themselves as better able to adopt sexual schema messages that framed sex as an important and enjoyable part of their lives showed increased sexual arousal, whereas better ability to adopt messages that framed sex as negative and unpleasant was associated with decreased sexual arousal (Kuffel \& Heiman, 2006). Moreover, the positively worded messages were rated as easier to 
adopt overall than negatively worded messages (Kuffel \& Heiman, 2006). More research is needed to understand whether gender and the ability to adopt or internalize messages may moderate the effectiveness of gain and loss frames on individuals' decisions to have sex.

\section{Partner Characteristics}

Unlike other health behaviors, most sexual behaviors involve a partner and are inherently interpersonal in nature. For instance, the decision to have sex could pose different types of risk depending on whether a person focuses primarily on potential costs to him- or herself (e.g., STI infection) or costs involving his or her sexual partner as well (e.g., uncomfortable discussions about condom use) (Devos-Comby \& Salovey, 2002; Kiene et al., 2005). While knowledge of a potential sexual partner's sexual history could also alter the relative costs, benefits, and level of uncertainty involved in making a decision to have sex with that individual, how different message frames affect decision making with highand low-risk partners has not been investigated previously. One may expect that a loss-framed message highlighting the potential costs of condomless sex may be more effective when deciding to have sex with an individual with a history of condom non-use and higher numbers of previous sex partners versus when deciding to have sex with an individual with a lower risk sexual history.

\section{Message Presentation Characteristics}

Finally, marketing and advertising research has shown that the order in which messages are presented can affect an audience's final judgments, decisions, or preferences (e.g., Buda \& Zhang, 2000). Messages that are more familiar, personally relevant, or attention-getting to the audience are more effective when presented first, whereas those that are less so are more effective when presented last (e.g., Haugtvedt \& Wegener, 1994). Given that young adults are exposed to both gain- and loss-framed sexual health messages in real life, understanding whether and how their presentation sequence impacts subsequent sexual decision making could have significant implications for the design of sexual health messaging and education targeted at this population. As young adults may be exposed primarily to messages focused on attention-getting, negative sexual health consequences like HIV or STIs, it is possible that loss-framed messages focused on these potential outcomes may be more powerful in reducing sexual risk taking when presented first. Yet, as most framing studies have employed between-groups designs in which participants are exposed to only one message frame, order effects in message framing are not well understood.

\section{The Current Study}

This study used a computerized sexual decision making task to examine the effect of gain- and loss-framed messages on decisions to have sex among single, heterosexual young adults. We also explored participants' gender, ability to adopt the messages during the task, prospective sexual partners' sexual history, and message presentation order as potential moderators of framing effects. Based on the previous findings indicating greater effectiveness of loss-framed messages when faced with greater perceived risk and uncertain outcomes, we expected loss-framed messages to more effectively reduce intentions to have sex, particularly with partners with a higher risk sexual history (i.e., higher numbers of lifetime sex partners and infrequent condom use). We also hypothesized that gain-framed messages may be more effective among women, and loss-framed messages among men given gender differences in perceived risk (Parsons et al., 2000; Toll et al., 2008). In addition, we expected that greater ability to adopt the messages would be associated with greater message framing effects. Finally, we expected loss-framed messages to be more effective when presented first, and less effective when presented second.

\section{Method}

\section{Participants}

Participants were recruited for a larger study via flyers and online advertisements in and around a large Midwestern university in the U.S. Participants were required to be a heterosexual man or woman between ages 18 and 24 years, sexually active, single and interested in casual dating and/or casual sex, have normal sexual functioning, and report having at least one sexual encounter (oral, anal, or vaginal sex) in the past three months. The analytic sample consisted of 127 men and women. Most participants were White, and racial and ethnic minority participants were oversampled relative to the demographic makeup of the study's location. More information about participants' demographics and sexual history is shown in Table 1.

\section{Procedure}

The university's Human Subjects Committee approved all study procedures. Interested parties contacted the laboratory to arrange a phone screening interview with a research assistant. Twentynine individuals were found ineligible to participate, and 130 qualified individuals were scheduled for the study; as a power outage erased experimental data for three participants, 127 participants comprised the analytic sample. Only one participant was tested at a time. Each participant gave written informed consent upon arrival to the lab, completed an online questionnaire battery, then a computerized decision making task, and an exit questionnaire. In total, the lab study lasted approximately $60-75 \mathrm{~min}$. After study completion, student participants were compensated with course credit, while others were paid $\$ 10 / \mathrm{h}$. 
Table 1 Participant characteristics stratified by gender

\begin{tabular}{|c|c|c|c|}
\hline & Total $(n=127)$ & $\begin{array}{c}\text { Men }(n=53) \\
M(S D)\end{array}$ & Women $(n=74)$ \\
\hline Age (in years) & $20.3(1.6)$ & $20.4(1.6)$ & $20.2(1.6)$ \\
\hline Age at first sex (in years) & $16.9(1.6)$ & $16.8(1.4)$ & $17.0(1.8)$ \\
\hline Number of lifetime sex partners (range 1-32) & $6.8(5.9)$ & $6.4(4.5)$ & $7.0(6.8)$ \\
\hline Number of partners with unprotected sex in last year (range 0-8) & $1.6(1.7)$ & $1.7(2.0)$ & $1.5(1.4)$ \\
\hline \multirow[t]{2}{*}{ Number of one-night stands (range $0-18$ ) } & $2.1(2.8)$ & $2.5(2.7)$ & $1.8(2.9)$ \\
\hline & \multicolumn{2}{|r|}{$n(\%)$} & \\
\hline \multicolumn{4}{|l|}{ Race } \\
\hline White & $100(78.7)$ & $43(81.1)$ & $57(77.0)$ \\
\hline Black & $12(9.4)$ & $3(5.7)$ & $9(12.2)$ \\
\hline Asian/Asian Indian & $9(7.1)$ & $4(7.6)$ & $5(6.8)$ \\
\hline Multiracial & $5(3.9)$ & $2(3.8)$ & $3(4.1)$ \\
\hline Hawaiian/Pacific Islander & $1(0.8)$ & $1(1.9)$ & $0(0.0)$ \\
\hline Hispanic/Latino ethnicity & $10(7.9)$ & $6(12.0)$ & $4(6.5)$ \\
\hline Ever been tested for STIs/HIV ${ }^{\mathrm{a}}$ & $71(55.9)$ & $15(21.1)$ & $56(78.9)$ \\
\hline Ever been diagnosed with $\mathrm{STI}^{\mathrm{b}}$ & $11(8.7)$ & $1(1.9)$ & $10(13.7)$ \\
\hline
\end{tabular}

${ }^{\mathrm{a}} p<.001 ;{ }^{\mathrm{b}} p<.05$, two-tailed

\section{Measures}

\section{Self-report Questionnaire}

Participants completed items assessing demographic information, sexual and relationship history, sexual health behaviors (e.g., condom use and one-night stands) used in previous research (Bancroft et al., 2003; Simpson \& Gangestad, 1991).

\section{Framed Messages}

Message creation was informed by the framing literature, previously successful sexual health messaging in Kuffel and Heiman (2006), and research indicating that portrayal of safe sex in a pleasurable, sensual way promotes risk-preventive attitudes (Scott-Sheldon \& Johnson, 2006) and is more attention-getting, persuasive, and appealing than non-sexual messages (Reichert, 2002). The first and last authors iteratively developed the messages and incorporated feedback from several undergraduate research assistants to ensure the messages' appropriateness for young adult men and women. Message wording was gender-specific, resulting in four messages in total, though message content was virtually identical. ${ }^{1}$ The messages were audio recorded, which has been found to be more persuasive than written messages (Braverman, 2008). All messages were recorded by a female narrator, and message excerpts are shown in Table 2.

\footnotetext{
${ }^{1}$ Message and instruction text is available from the corresponding author by request.
}

Loss-framed messages focused on how not using condoms may lead to negative consequences (e.g., not taking care of their and their partner's sexual health, feeling less pleasure because of increased concern about negative consequences of not using condoms), and gain-framed messages focused on how condom use may lead to positive outcomes in these areas (e.g., feeling good about oneself for protecting their and their partner's sexual health; feeling more pleasure because of less fear of negative consequences). Based on the feedback from the research assistants, the message alluded to, but did not explicitly mention, negative outcomes like STIs, HIV, or unwanted pregnancy in order to maintain sensual appeal. Each message was preceded by a set of verbal instructions and followed by a brief reminder to remember and attempt to internalize the message during the laboratory task. Together, the instructions and messages lasted approximately $1.5 \mathrm{~min}$.

\section{Decision Making Task}

Decision making was measured using a computerized task adapted from past studies (Prause, Staley, \& Finn, 2011; Rupp et al., 2009). Participants were instructed to imagine that they were at a bar and interested in meeting a partner for a casual "hook up" that evening. Participants were instructed to rate their likelihood of having sex with hypothetical partners based on the partners' sexual history, which was presented on the screen.

The task was presented using DirectRT v2008 (Empirisoft Corporation, New York, NY) and consisted of a series of trials that each contained a grayscale photograph $(640 \times 480$ pixels $)$ of a 
Table 2 Excerpts from gain- and loss-framed messages

\begin{tabular}{lc}
\hline Gain-framed message & Loss-framed message \\
\hline $\begin{array}{c}\text { Sex is important to you, and you know that when you and your partner make } \\
\text { condoms a part of your sexual experience, youfeel more adventurous and }\end{array}$ & $\begin{array}{c}\text { Sex is important to you, and you know that when you and your partner } \\
\text { don't make condoms a part of your sexual experience you don'tfeel as } \\
\text { adventurous or free }\end{array}$ \\
$\begin{array}{c}\text { When you and your partner use condoms, you feel like you can lose your } \\
\text { inhibitions and really let go }\end{array}$ \\
$\begin{array}{c}\text { When you and your partner don't use condoms, you feel like you can't } \\
\text { really let go } \\
\text { your partner }\end{array}$ \\
$\begin{array}{c}\text { Without condoms, you feel like you're not taking care of your sexual } \\
\text { health or your partner }\end{array}$
\end{tabular}

Italics denote differences between messages

hypothetical sex partner centered on a black computer screen. All pictures were obtained from the public domain. Participants were presented with faces of other-sex individuals who appeared to be similar in age to the participants. Faces were used instead of fullbody photographs to control for the amount of information participants used to make their decisions. The lower left side of the screen displayed a number representing the hypothetical partner's past sex partners (1-4 or 10-13), while the lower right side of the screen displayed a word ("usually" or "rarely") that indicated how often the individual used condoms in the past. Partners were categorized as either "low risk" (i.e., 1-4 partners and usually used condoms) or "high risk" (i.e., 10-13 partners and rarely used condoms), though participants were not informed about this distinction.

The task consisted of three blocks of 16 trials. Each block of trials consisted of 8 each of high- and low-risk partners, which were presented in randomized order. Faces were randomly paired with either low- or high-risk information, and each face was used only once per participant. Participants rated their intentions to have sex with the hypothetical partner by pressing one of four computer keys that corresponded to a 4-point Likert scale $(1=$ very unlikely; $4=$ very likely). Each trial lasted $10 \mathrm{~s}$, and the task automatically advanced to the next trial.

The first block of trials obtained a baseline measure of participants' intentions to have sex with the hypothetical partners. The second and third blocks were preceded by either the gain- or lossframed messages, such that each participant listened to both messages during the experiment. In an attempt to minimize order and carryover effects, the messages were counterbalanced across participants, and a 3-min nature film was presented between the second and third blocks. The task took approximately $15 \mathrm{~min}$ to complete.

\section{Exit Questionnaire}

Several items assessed participants' impressions of the framed messages. First, participants were asked whether they perceived any differences between the two audio messages and, if so, to describe the differences. Participants who could not tell the difference between the two messages were not required to complete the remaining items. Then, participants' ability to adopt or internalize the messages was measured (Kuffel \& Heiman, 2006;
Middleton, Kuffel, \& Heiman, 2008). Since participants were not told that the messages differed, these items asked participants to evaluate their ability to adopt either the first or the second message (e.g., "Regarding the FIRST message you heard, how able were you to take on or 'try on' the sexual messages during the task?"). These items were rated using a 5-point Likert scale $(1=$ not at all; $5=$ extremely).

\section{Results}

\section{Participant Gender, Message Order, Partner Risk, and Message Frame on Sexual Decision Making}

A 2 (Participant Gender: male/female) $\times 2$ (Message Order: gain frame first/loss frame first $) \times 2$ (Partner Risk: high/low $) \times 3$ (Message Frame: no frame/gain/loss) multivariate repeated measures analysis of variance (MANOVA) was conducted on participants' intentions to have sex. Only the main effects and the interactions of interest (i.e., Participant Gender $\times$ Message Frame, Participant Gender $\times$ Partner Risk, Message Order $\times$ Message Frame, Message Frame $\times$ Partner Risk) were investigated and are reported below.

Analyses yielded significant effects of Participant Gender, $F(1,123)=24.44, p<.001, \eta_{p}^{2}=.17$, Partner Risk, $F(1,123)=$ $315.47, p<.001, \eta_{p}^{2}=.72$, and Message Frame, $F(2,246)=4.15$, $p=.02, \eta_{p}^{2}=.03$. The effect of Message Order was not significant, $F(1,123)=1.13, p=.29, \eta_{p}^{2}=.01$. These main effects were qualified by several two-way interactions.

First, there was a significant Participant Gender $\times$ Message Frame interaction, $F(2,246)=6.31, p=.002, \eta_{p}^{2}=.05$. Followup tests revealed that all significant comparisons occurred within, and not between, participants' gender. Among male participants, intentions to have sex were significantly weaker in the lossframed condition $(M=2.35, S E=.05)$ compared to baseline $(M=2.53, S E=.06, p=.001)$ and the gain-framed condition $(M=2.46, S E=.04, p=.007)$. Among female participants, intentions to have sex were significantly weaker at baseline $(M=$ $2.10, S E=.05)$ relative to the gain-framed condition $(M=2.20$, $S E=.04, p=.03)$. There were no significant differences between 
the loss-framed condition $(M=2.14, S E=.05)$ and the baseline and gain-framed blocks among female participants.

Second, as expected, there was a significant Message Order $\times$ Message Frame interaction, $F(2,246)=4.20, p=.02, \eta_{p}^{2}=.03$. Pairwise comparisons focused on the loss- and gain-framed conditions and not the baseline condition, which was presented first for all participants. Analyses revealed that among participants who received the gain-framed message first, there were stronger intentions to have sex after listening to the gain-framed message $(M=2.41, S E=.05)$ than after the loss-framed message $(M=$ 2.23, $S E=.05, p<.001$; Fig. 1). Compared to participants who received the loss-framed message first $(M=2.25, S E=.05)$, participants who received the gain-framed message first had significantly stronger intentions to have sex in the gain-framed condition $(M=2.41, S E=.07, p=.02)$. There were no other significant differences in intentions to have sex related to message presentation order.

Third, there was a significant Message Frame $\times$ Partner Risk interaction, $F(2,246)=15.64, p<.001, \eta_{p}^{2}=.11$. Consistent with predictions, follow-up tests using pairwise comparisons indicated that participants had significantly weaker intentions to have sex with the high-risk partners after listening to the loss-framed message $(M=1.51, S E=.05)$ than after the gain-framed message $(M=1.64, S E=.05, p<.001$; Fig. 2). There was no significant difference between message frames on participants' intentions to have sex with low-risk partners $(p=.43)$.

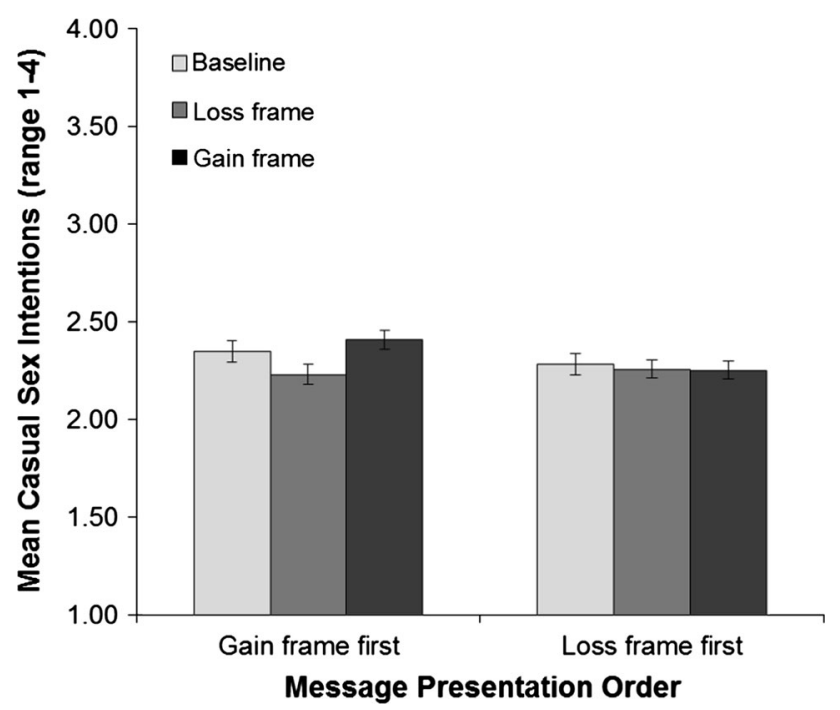

Fig. 1 Message Order $\times$ Message Frame interaction. Among participants who received the gain-framed message first, there were significantly stronger intentions to have sex after listening to the gain-framed message compared to the loss-framed message $(p<.001)$. Compared to participants who received the loss-framed message first, participants who received the gain-framed message first had significantly stronger intentions to have sex in the gain-framed condition $(p=.02)$. Among those who received the loss-framed message first, there were no significant differences in intentions to have sex across conditions

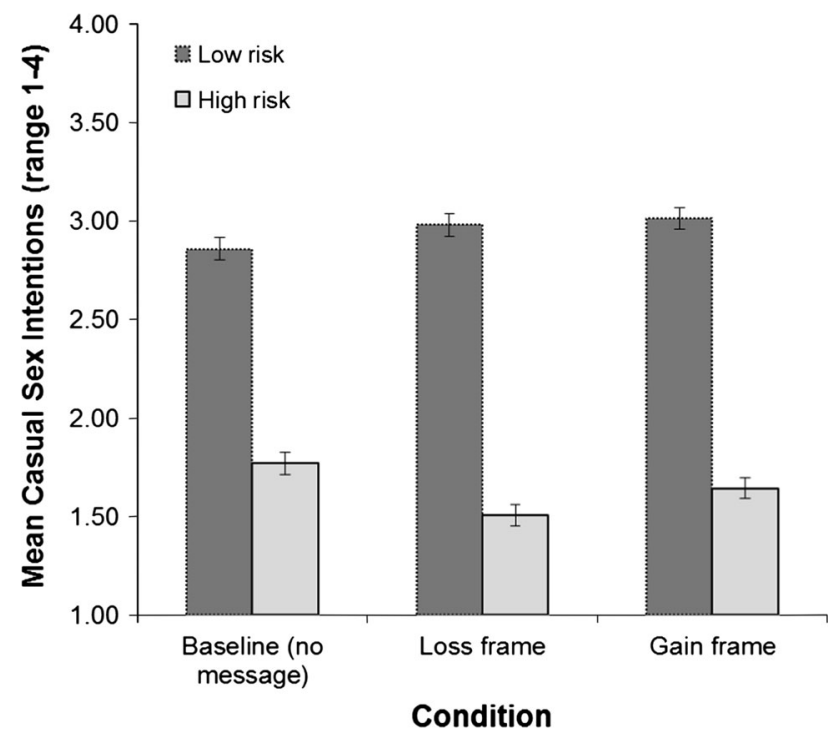

Fig. 2 Interaction of Partner Risk and Message Frame. Compared to baseline and the gain-framed message conditions, the loss-framed message was associated with significantly weaker intentions to have sex with high-risk sexual partners $(p<.001)$. There were no significant differences in participants' intentions to have sex with low-risk partners $(p=.43)$. The graph also illustrates the main effect of Partner Risk, with significantly weaker intentions to have sex with high-risk partners than with low-risk partners $(p<.001)$

Finally, the Participant Gender $\times$ Partner Risk interaction was not significant, $F(1,123)=2.14, p=.14, \eta_{p}^{2}=.02$. Male and female participants did not differ in their likelihood of having sex with high- versus low-risk partners.

\section{Ability to Adopt Framed Messages and Sexual Decision Making}

A majority (55.8\%) of participants were able to detect differences between the two messages. Some participants who were unable to discriminate between the messages did not respond to items about their ability to adopt each message, so in the following results, degrees of freedom vary from the previous analyses. A 2 (Participant Gender) $\times 2$ (Message Frame) MANOVA examined the extent to which men and women were able to adopt the messages. A main effect of Participant Gender, $F(1,88)=5.04, p=.03$, $\eta_{p}^{2}=.06$, indicated that women were better able to adopt the framed messages $(M=4.06, S E=.13)$ than men $(M=3.60$, $S E=.16)$. A main effect of Message Frame, $F(1,88)=5.09, p=$ $.03, \eta_{p}^{2}=.72$, indicated that participants felt that the gain-framed message was easier to adopt $(M=3.92, S E=.11)$ than the lossframed message $(M=3.73, S E=.11)$. The Message Frame $\times$ Participant Gender interaction was not significant, $F(1,88)=$ $.003, p=.96, \eta_{p}^{2}=.05$, showing that men and women did not differ in their ability to adopt the gain- and loss-framed messages.

Analyses then examined whether the ability to adopt the messages was linked with stronger or weaker intentions to have sex. The two items measuring participants' ability to adopt the mes- 
sages were summed to form a composite score of overall ability to internalize the messages (Cronbach alpha $=.95)$, and a median split was used to produce two groups of participants who were more able and less able to adopt the messages. One-way ANOVAs revealed that participants who were more able to adopt the messages had significantly weaker intentions to have sex with high-risk partners $(M=1.46, S E=.06)$ than participants less able to adopt the messages $(M=1.73, S E=.09 ; F(1,99)=6.28$, $\left.p=.01, \eta^{2}=.06\right)$. There was no significant effect of ability to adopt the messages on participants' intentions to have sex with low-risk partners (less able: $M=2.93, S E=.08$; more able: $\left.M=2.95, S E=.08 ; F(1,99)=.04, p=.84, \eta^{2}=.00\right)$.

\section{Discussion}

To our knowledge, this was among the first studies to examine the effects of framed messages on young adults' intentions to have sex and to assess the impact of message order on sexual decision making. Findings largely supported our predictions. Compared to the gain-framed message, the loss-framed message was associated with weaker intentions to have sex, especially with partners whose sexual history was indicative of higher STI risk as indicated by medium-to-large effect sizes. Message presentation order had a small but significant impact on intentions to have sex such that after listening to the gain-framed message first, participants' intentions increased slightly, but then decreased after the loss-framed message. In contrast, when participants listened to the loss-framed message first, intentions to have sex did not significantly differ by message frame. In addition, there was a mediumsized effect of participants' ability to internalize messages on intentions to have sex with high-risk partners. Together, the findings show that characteristics of the message recipient, sexual partner, and the message and its delivery can affect sexual decision making, and suggest that interactions between these variables should be considered when tailoring framed sexual health messages for young adults.

The impact of the framed messages in this study was consistent with prospect theory (Tversky \& Kahneman, 1981), which proposes that loss-framed messages are more persuasive in situations that pose greater risks and have uncertain outcomes. This has implications for designing sexual health promotion and STI prevention messages. Recent interventions targeted at improving sexual health and reducing STI rates have tended to emphasize positive aspects of safe sex or approach sex from a holistic, sexpositive perspective (e.g., Robinson, Bockting, Rosser, Miner, \& Coleman, 2002) over a focus on potentially negative consequences of sex. While this positive approach is arguably important for promoting healthy sexuality in general, certain situations or groups of people may benefit primarily from loss-framed sexual health appeals (e.g., Richardson et al., 2004), highlighting the importance of tailoring message content and delivery by population or context.
For instance, the present study suggests that loss-framed messages may be especially valuable for people who are deciding whether to have sex with new partners or casual partners who pose a higher risk for STIs. Further research should investigate whether gainframed messages may be useful in sexual situations with lower risk and uncertainty, such as deciding whether to use condoms with regular, ostensibly monogamous partners perceived to pose a lower risk of STIs. In addition, though the loss-framed message was more effective, participants found the gain-framed message substantially easier to internalize, as indicated by the large effect size. This suggests that it is critical for intervention developers to ensure that gainand loss-framed health promotion messages are not only effective, but also easy to adopt and resonate with the intended recipients. Finally, a crucial feature of the loss-framed message in this study was its emphasis on condom use as a way to show care and responsibility for oneself and one's partner, rather than focusing primarily on the negative consequences of STIs-an approach distinct from earlier STI/HIV prevention messages' reliance on fear appeals (e.g., Witte, 1991). Young adults' responsiveness to the messages in this study provides additional support for using sexual health messages that focus on how sexual decisions affect both oneself and one's partner (e.g., Kiene et al., 2005).

Participants in this study received both message frames, whose effectiveness varied according to message presentation order. One potential explanation of the order effects is that the loss-framed messages, which appeared to be more effective overall, may have carried over to the remainder of the task among the participants who received this message first. Given that young people likely are exposed to messages that convey both negative and positive consequences of sex in the real world, understanding the effects of order and timing of framed messages may help health communications and public health professionals determine the optimal message presentation sequences for improving different sexual health outcomes for this vulnerable population. Past research has suggested that different factors can lead to primacy or recency effects in persuasive messaging, such as whether the message topic is interesting, controversial, or familiar to the message recipient, or the message recipient's ability to engage in effortful processing of the message (e.g., Haugtvedt \& Wegener, 1994). Moreover, developmental factors such as impulsivity, or a dispositional tendency to be risk-seeking or risk-averse, may impact young adults' receptiveness to messages focused on individual or relational, and proximal or distal consequences of their sexual behavior. As our analyses on message order were exploratory, however, the specific mechanisms underlying the order effects in this study are unclear. Moreover, as the order effect was relatively small, it is important to investigate further whether message sequence could have a noticeable impact on actual health behavior. This underscores the need for additional research to help determine whether hearing one sexual health message or multiple messages, and in what order, works best for whom and in what situations.

Participants who were better able to internalize the messages showed weaker intentions to have sex with high-risk but not with 
low-risk partners. Likewise, framing effects were observed for intentions to have sex with high-risk but not low-risk partners. While these findings potentially could be attributed to the effectiveness of the messages, it is also possible that participants' perceived risks of having sex with the low-risk partners were so low that whether they heard or internalized messages advocating safe sex was inconsequential for their decision making. This finding was consistent with research demonstrating that perceiving a potential partner to be of lower risk for STIs/HIV is linked with stronger intentions to engage in risky sexual behavior (e.g., Vanable, Ostrow, McKirnan, Taywaditep, \& Hope, 2000). Educational efforts aimed at improving sexual decision making should stress the fact that prospective partners who report few sexual partners or frequent condom use does not always mean that that partner is free of risk, which may, in turn, improve individuals' receptiveness to STI prevention or sexual health promotion messaging regardless of a partner's actual or perceived risk. Regardless, the fact that participants who were better able to internalize the messages had weaker intentions to have sex with higher risk partners emphasizes that in order for sexual health messages to be effective, their content and tone should be believable, palatable, and resonant with the intended audience.

While women overall had weaker intentions to have sex than men, intentions differed as a function of message frame among men, and women had slightly weaker intentions at baseline relative to the message frame conditions. This finding provides some support for within-gender differences in sexual health messaging observed in previous research (O'Connor et al., 2005). One possible explanation for our finding is that the framed messages in this study had a gender-based personal relevance (e.g., O'Connor et al., 2005). In other words, the framed messages focused on condom use, which, while relevant to both men and women in a heterosexual encounter, ultimately is contingent on the behavior of a male partner. Thus, it follows that men's intentions were more influenced by condom-related messages compared to women. Given the scant research on gender differences in health behavior messaging studies, more research is needed to understand possible reasons for gender differences in message framing effects. In addition, as our findings showed a small-to-medium effect size of gender and framing on intentions to have sex, further inquiry in this area can shed light on whether gender-specific versus non-specific messages have a noticeable impact on men's and women's sexual health behaviors.

Our study design was distinct from previous framing studies in several ways. First, most other studies typically present only one message frame to participants, while ours were exposed to both gain- and loss-framed messages. This was intended to reflect the likelihood that most individuals will, at some point, hear both types of sexual health messages in real life. Second, we assessed participants' behavioral intentions over a number of trials, whereas previous studies often used a single item to assess behavioral intentions. Finally, the content and delivery of the messages differed from most sexual health framing studies. The messages were delivered in audio format and in addition to the framed statements, they described condom use as a way to show care and responsibility for oneself and one's partner, rather than focusing primarily on the negative consequences of STIs. These messages arguably may have been more engaging and easier for participants to internalize than messages presented written or visually, or messages that simply described benefits and costs of a particular behavior.

\section{Limitations}

The findings should be considered in light of the study's limitations. First, prior studies have examined the effect of framed messages concerning a particular behavior (e.g., impact of condom use on STI infection) on its corresponding outcome (e.g., selfreports of condom use or condom use intentions). In contrast, in this study, the topic of the messages (condom use) and the dependent variables of interest (intentions to have sex with a high/low risk partner) did not directly correspond. Yet, this study's findings provide evidence that framed sexual health messages advocating or discouraging one behavior can generalize to, and have a positive impact on, other health behaviors that are closely related. Second, the risk intent task provided information about the potential partner's sexual history and facial appearance only. In contrast, in-person encounters allow individuals to base their impressions of potential partners on full-body appearances, and one may know little, if anything, about the potential partners' sexual history. However, this study's approach arguably does have validity, as the task could reflect similar aspects of online dating or "hookup" sites in which one must make a decision based on limited information. Moreover, this study examined participants' intentions to have sex in a laboratory setting, rather than reports of real-world STI risk behaviors following the study. While intentions are predictive of actual behavior (Ajzen, 1991), future research could extend the present findings by examining the impact of message framing on decisions to have sex in real life. Finally, though the sample consisted of young adults at behaviorally higher risk for STIs (CDC, 2014), the participants were primarily white, heterosexual, and living in a semi-rural Midwestern city, so findings may not generalize to other groups at high risk for STIs, such as younger adolescents or racially diverse young men who have sex with men (CDC, 2014).

\section{Conclusion}

Together, the findings from this study show that a combination of message frame, presentation order, and characteristics of the message recipient and potential sexual partner impacts young adults' sexual decision making. Future research is needed in several areas. For example, it will be important to assess framed messages' long-term impact on real-world sexual decisions in groups of people at differential risk for STIs and HIV. Research should also determine the conditions that foster optimal message effectiveness, including whether presenting framed messages during 
different stages of behavior change (Prochaska \& DiClemente, 1986), multiple versus single messages, or different messaging sequences could produce sustained changes in safer-sex attitudes, intentions, and behaviors.

Acknowledgments Data collection was supported in part by predoctoral fellowships to the first author (F31 MH090895 and TL1 RR025759) and R01 DA017924 to Peter Finn. We are grateful to Caitlin Anderson, Rebeka Schwartz, and Loren Twigg, who assisted with data collection and processing, and to Heather Rupp and Thomas James, who gave feedback on earlier drafts of this article.

\section{References}

Ajzen, I. (1991). The theory of planned behavior. Organizational Behavior and Human Decision Processes, 50, 179-211. doi:10.1016/0749-5978 (91) $90020-\mathrm{t}$.

Apanovitch, A. M., McCarthy, D., \& Salovey, P. (2003). Using message framing to motivate HIV testing among low-income, ethnic minority women. Health Psychology, 22, 60-67. doi:10.1037/0278-6133.22.1. 60.

Bancroft, J., Janssen, E., Strong, D., Carnes, L., Vukadinovic, Z., \& Long, J. S. (2003). Sexual risk-taking in gay men: The relevance of sexual arous ability, mood, and sensation seeking. Archives of Sexual Behavior, 32, 555-572. doi:10.1023/A:1026041628364.

Block, L. G., \& Keller, P. A. (1995). When to accentuate the negative: The effects of perceived efficacy and message framing on intentions to perform a health-related behavior. Journal of Marketing Research, 32, 192-203.

Braverman, J. (2008). Testimonials versus informational persuasive messages. Communication Research, 35, 666-694. doi:10.1177/0093650 208321785.

Buda, R., \& Zhang, Y.(2000). Consumer product evaluation: The interactive effect of message framing, presentation order, and source credibility. Journal of Product \& Brand Management, 9, 229-242.

Camenga, D. R., Hieftje, K. D., Fiellin, L. E., Edelman, E. J., Rosenthal, M. S., \& Duncan, L. R. (2014). The use of message framing to promote sexual risk reduction in young adolescents: A pilot exploratory study. Health Education Research, 29, 360-366. doi:10.1093/her/cyt156.

Centers for Disease Control and Prevention (CDC). (2014). Sexually transmitted disease surveillance 2013. Atlanta, GA: U.S. Department of Health and Human Services.

Covey, J. (2014). The role of dispositional factors in moderating message framing effects. Health Psychology, 33, 52-65. doi:10.1037/a0029305.

Devos-Comby, L., \& Salovey, P. (2002). Applying persuasion strategies to alter HIV-relevant thoughts and behavior. Review of General Psychology, 6, 287-304. doi:10.1037/1089-2680.6.3.287.

Gallagher, K. M., \& Updegraff, J. A. (2012). Health message framing effects on attitudes, intentions, and behavior: A meta-analytic review. Annals of Behavioral Medicine, 43, 101-116. doi:10.1007/s12160-011-9308-7.

Garcia-Retamero, R., \& Cokely, E. T. (2011). Effective communication of risks to young adults: Using message framing and visual aids to increase condom use and STD screening. Journal of Experimental Psychology: Applied, 17, 270-287. doi:10.1037/a0023677.

Gerend, M. A., \& Shepherd, J. E. (2007). Using message framing to promote acceptance of the human papillomavirus vaccine. Health Psychology, 26, 745-752. doi:10.1037/0278-6133.26.6.745.

Haugtvedt, C.P., \& Wegener, D. T. (1994). Message order effects in persuasion: An attitude strength perspective. Journal of Consumer Research, 21, 205-218. doi:10.1086/209393.
Hull, S. J. (2012). Perceived risk as a moderator of the effectiveness of framed HIV-test promotion messages among women: A randomized controlled trial. Health Psychology, 31, 114-121. doi:10.1037/a0024702.

Kiene, S. M., Barta, W. D., Zelenski, J. M., \& Cothran, D. L. (2005). Why are you bringing up condoms now? The effect of message content on framing effects of condom use messages. Health Psychology, 24, 321-326. doi:10.1037/0278-6133.24.3.321.

Kuffel, S. W., \& Heiman, J. R. (2006). Effects of depressive symptoms and experimentally adopted schemas on sexual arousal and affect in sexually healthy women. Archives of Sexual Behavior, 35, 163-177. doi: 10.1007/s10508-005-9015-1.

Middleton, L. S., Kuffel, S. W., \& Heiman, J. R. (2008). Effects of experimentally adopted sexual schemas on vaginal response and subjective sexual arousal: A comparison between women with sexual arousal disorder and sexually healthy women. Archives of Sexual Behavior, 37, 950-961. doi:10.1007/s10508-007-9310-0.

O'Connor, D. B., Ferguson, E., \& O'Connor, R. C. (2005). Intentions to use hormonal male contraception: The role of message framing, attitudes and stress appraisals. British Journal of Psychology, 96, 351-369. doi:10.1348/000712605X49114.

Parsons, J. T., Halkitis, P. N., Bimbi, D., \& Borkowski, T. (2000). Perceptions of the benefits and costs associated with condom use and unprotected sex among late adolescent college students. Journal of Adolescence, 23, 377-391. doi:10.1006/jado.2000.0326.

Prause, N., Staley, C., \& Finn, P. (2011). The effects of acute ethanol consumption on sexual response and sexual risk-taking intent. Archives of Sexual Behavior, 40, 373-384. doi:10.1007/s10508-010-9718-9.

Prochaska, J. O., \& DiClemente, C. C. (1986). Toward a comprehensive model of change. In W.R. Miller \& N. Heather(Eds.), Treating addictive behaviors: Processes of change (Vol. 13, pp. 3-27). New York: Springer.

Reichert, T. (2002). Sex in advertising research: A review of content, effects, and functions of sexual information in consumer advertising. Annual Review of Sex Research, 13, 241-273. doi:10.1080/10532528.2002. 10559806.

Richardson, J.L., Milam, J., McCutchan, A., Stoyanoff, S., Bolan, R., Weiss, J., ... Marks, G. (2004). Effect of brief safer-sex counseling by medical providers to HIV-1 seropositive patients: A multi-clinic assessment. AIDS, 18, 1179-1186. doi:10.1097/00002030-200405210-00011.

Robinson, B.E., Bockting, W. O., Rosser, B. R. S., Miner, M., \& Coleman, E. (2002). The sexual health model: Application of a sexological approach to HIV prevention. Health Education Research, 17, 43-57. doi:10. 1093/her/17.1.43.

Rothman, A. J., \& Salovey,P. (1997). Shaping perceptions to motivate healthy behavior: The role of message framing. Psychological Bulletin, 121, 319. doi:10.1037/0033-2909.121.1.3.

Rupp, H. A., James, T. W., Ketterson, E. D., Sengelaub, D. R., Janssen, E., \& Heiman, J. R. (2009). The role of the anterior cingulate cortex in women's sexual decision making. Neuroscience Letters, 449, 42-47. doi:10.1016/j.neulet.2008.10.083.

Scott-Sheldon, L. A., \& Johnson, B. T. (2006). Eroticizing creates safer sex: A research synthesis. Journal of Primary Prevention, 27, 619-640. doi:10.1007/s10935-006-0059-3.

Simpson, J. A., \& Gangestad, S. W. (1991). Individual differences in sociosexuality: Evidence for convergent and discriminant validity. Journal of Personality and Social Psychology, 60, 870-883. doi:10.1037/00223514.60.6.870

Toll, B. A., Salovey, P., O’Malley, S. S., Mazure, C. M., Latimer, A., \& McKee, S. A. (2008). Message framing for smoking cessation: The inter action of risk perceptions and gender. Nicotine \& Tobacco Research, 10, 195-200. doi:10.1080/14622200701767803.

Tversky, A., \& Kahneman, D. (1981). The framing of decisions and the psychology of choice. Science, 211, 453-458. doi:10.1126/science.7455 683. 
United States Department of Health and Human Services, Healthy People 2020. (2013). Reproductive and sexual health. Retrieved from http:// www.healthypeople.gov/2020/LHI/reproductiveHealth.aspx.

Vanable, P. A., Ostrow, D. G., McKirnan, D. J., Taywaditep, K. J., \& Hope, B. A. (2000). Impact of combination therapies on HIV risk perceptions and sexual risk among HIV-positive and HIV-negative gay and bisexual men. Health Psychology, 19, 134-145. doi:10.1037/0278-6133.19.2. 134.

Witte, K. (1991). The role of threat and efficacy in AIDS prevention. International Quarterly of Community Health Education, 12, 225-249. doi:10.2190/U43P-9QLX-HJ5P-U2J5. 